\title{
DISPARITIES OF POTENTIAL GAINS IN LIFE EXPECTANCY DEVELOPMENT BETWEEN THE SLOVAK REPUBLIC AND THE CZECH REPUBLIC
}

\author{
Tatiana Vagašová, Beáta Gavurová \\ Faculty of Economics, Technical University of Košice, Košice, Slovak Republic
}

\section{SUMMARY}

Aim: The purpose of this paper is to determine how many years a person could be expected to live if a specific cause of death was eliminated, and to compare potential gains in life expectancy (PGLES) between Slovakia (SVK) and the Czech Republic (CZE).

Methods: PGLEs were computed from mortality reports (1996-2013) for deaths from the main groups of chronic diseases, namely ischaemic heart disease (IHD), cerebrovascular diseases (CVD), cancer (CA), diabetes mellitus (DM), and chronic respiratory diseases (CRD) for the Slovak and Czech populations in five-year age groups. Country comparative analysis was conducted by constructing rate ratios of PGLES.

Results: In 2013, life expectancy at birth for the Slovak and Czech populations was 76.5 and 78.3 years. Overall trends of standardised mortality rates of chronic diseases roughly paralleled the PGLEs trend. During 1996-2013, SVK reported the highest PGLEs of IHD at an average of 4.54 years, compared to PGLEs of CA reaching a value of 3.61 years in CZE. The PGLES of IHD showed the largest gap between SVK and CZE, with an average of 1.65 higher values in SVK. With the elimination of CVD as the third most influential disease in both countries, PGLEs decreased from 1.65 to 0.93 years in CZE; a negligible drop from 1.13 to 1.05 was recorded in SVK. The lowest impacts on life expectancy were recorded in DM and CRD. However, since 2005 these trends have deteriorated in CZE. In 2013, IHD had a similar impact on life expectancy in all age groups in SVK and a decreasing impact among 50-54 year olds in CZE. Similarly to SVK, people in CZE aged $45-49$ could gain 0.94 years in LE after CVD elimination, which is nearly the same as at birth.

Conclusions: The higher the life expectancy after elimination of the cause of death is, the higher the impact of the disease on life expectancy. Health prevention programs should be mainly aimed at CA mortality in CZE, while the highest burden of IHD is seen in SVK.

Key words: life expectancy, potential gains in life expectancy, standardised mortality rate, non-communicable diseases, Slovak Republic, Czech Republic

Address for correspondence: B. Gavurová, Faculty of Economics, Technical University of Košice, Němcovej 32, Košice, Slovak Republic. E-mail: beata.gavurova@tuke.sk

https://doi.org/10.21101/cejph.a4955

\section{INTRODUCTION}

In recent decades, there has been a heterogeneous development of LE across countries influenced by political, social and economic changes. The countries of the former Soviet Union have reported significant changes in life expectancy after transition in 1989. As we consider countries of the Visegrad Group, the Czech Republic experienced improvement from 1989 to 2013 by 6.7 years compared to 5.3 years in Slovakia, while Poland and Hungary prolonged life expectancy by nearly the same, respectively, 6.3, 6.2 years (1).

Differences in life expectancy can be explained by many risk factors that are both specific to each disease, on the other hand, many diseases are affected by the same risk factors, like chronic diseases (2-4). Non-communicable diseases are responsible for nearly two thirds of all deaths (in Slovakia recently even more) and exhibit about 50\% of global burden diseases (5). Currently, cardiovascular diseases are the most common cause of death for men and women in Europe, including Slovakia and Czech Republic (6).
Purpose of this paper is to offer information how many years people would live longer, if the chronic causes of death were eliminated, comparing Slovakia and Czech Republic. These results could be useful for health decision making, planning, and measuring the effectiveness of health care system financing (7-9).

In the literature, a common indicator used in assessment of the impact of disease elimination on life expectancy is the "potential gains in life expectancies" (10-13). Conversely, these analyses are missing in evaluation of the public health interventions in SVK and CZE. Some studies (14-16) examined that improvement of health status of population after 1989 results from several interacting factors. For instance, health care improvement made by increasing funds in health care system, market opening, access to the latest medical technology, methods, approaches, and also the availability of a wide range of the most modern medicaments. Targeted screenings of at-risk groups of people, a need for a healthy lifestyle, and individual care for health have an important role in an implementation of prevention programs $(17,18)$. These are closely related to the rising living standards, similarly, to the improvement of living and working environment. 
The aim of the paper is to compare potential gains in life expectancy after the elimination of ischaemic heart disease (IHD), cancer (CA), cerebrovascular diseases (CVD), diabetes mellitus (DM), and chronic respiratory diseases (CRD) from 1996 to 2013 by age groups between CZE and SVK.

\section{MATERIALS AND METHODS}

The data on cause-specific mortality by age groups were obtained from WHO mortality database in the case of CZE, and from National Health Information Centre of Slovakia (under the conditions of the contract).

Potential gains in life expectancy, both in Slovakia and Czech Republic, were calculated according to the methodical tutorials of Demographic Research Centre (19) and National Vital Statistics Reports (20), using the abridged life-tables technique. The sum up, firstly, age-specific mortality rates and the life expectancy (ex) expressing the all causes of deaths by five-year age groups were exhibited. Secondly, we subsequently calculated probabilities of survival $\left({ }_{n} p_{x}\right)$, the probabilities of death eliminating the ith cause $\left({ }_{n} q_{x}^{(-i)}\right)$, the number of person-years lived $\left({ }_{n} L_{x}^{(-i)}\right)$ in the age interval $x$ to $x+n$, and the number of person-years lived after exact age $x\left(T_{x}\right)$. Thirdly, the cause-eliminated life expectancy $\left(e_{x}^{(-i)}\right)$ by elimination of the specific causes of deaths was estimated, and finally, the potential gains in life expectancy of a certain disease by age groups were examined as a difference between life expectancy and cause-eliminated life expectancy.

Standardised mortality rates were composed by direct standardisation using the European standard population (21).

The rate ratio indicates how much higher or lower is the potential gains in life expectancy of a certain disease (i) in Slovakia relative to the PGLE of the same disease in the Czech Republic. It is expressed by formula:

$$
\text { Rate Ratio }=\frac{P G L E_{S V K, i}}{P G L E_{C Z E, i}}
$$

\section{RESULTS}

\section{Trends of Life Expectancy and Disease Mortality}

In 1987, already two years before the velvet revolution, LE in CZE reached a value of 71.6 years, while in SVK 71.4 years. Since the velvet revolution in 1989, the scissors-like difference has still extended. In 2013, LE in CZE gained a number of 78.3 years, an increase of 6.7 years, compared to an increase by 5.1 years on the 76.5 years in SVK. However, they did not achieve the LE at birth across the $28 \mathrm{EU}$ member states reached 80.6 years on average in 2013.

Comparing the standardised mortality rates of the specific groups of chronic diseases between SVK and CZE, the highest difference is seen in IHD when the values of SMR are significantly higher in SVK during the whole time period (Fig. 1).

Between 1996 and 2013, the standardised mortality rates of IHD decreased by $10.4 \%$, from $528.6 / 100,000$ inhabitants to 473.5/100,000 in SVK, and by 18.3\% in CZE, from 445.3/100,000 to 363.8/100,000. At first, between 1996 and 2001, opposite trends were recognised between SVK and CZE, when the SMR of IHD raised by $10.5 \%$ in SVK, compared to the drop by $19 \%$ in CZE. This positive development of the SMR in CZE was influenced by the most significant factors, like an implementation of preventive screening programs, new treatment methods, significant rise of cardiovascular surgical procedures, better availability of modern medical technology, etc. (22). SVK lagged in a transformation of health care system in many dimensions, mainly in financing of health care system, what reflected the obstacle to develop preventive, diagnostic and therapeutic processes (23). From the year 2002 the trend was cyclical, in the same direction, both in CZE and SVK. The second highest peak was recorded in 2008 what can relate to the global economic crisis. In the last examined years, SMR reported decreasing trend in SVK, on the contrary to the slightly increasing trend in CZE.

As for SMR from cancer, SVK has reached slightly better values than CZE. From the beginning of the period to the year 2004, the trend of SMR was stagnated in CZE. On the other hand, during the time span 1996-2013, a percent decrease of SMR at a value of 23.4\% was meaningfully higher in CZE, than a decreasing rate at a value of $4.1 \%$ in SVK. Better dynamics of SMR decrease can be the result of an implementation of mammography screening for women aged 45-69 years in 2002, although in the light of recent evidence questioning the real impact of mammography, other explanations should also be considered. Since 2008 and 2009, cervical screening program and colorectal cancer screening have been launched in CZE (23).

As for the development of SMR from CVD, the SMR were an average of 55.6\% higher in CZE than in SVK during the 1996 and 2007. An opposite trend occurred from 2008, since the values of SMR had been lower in CZE. Dynamics of SMR decline was again higher in CZE (54.3\%) compared to the SVK (23.7\%). For example, this can be the result of operating the stroke centres with 24/7 thrombolysis in CZE.

On the contrary, SMR of CRD and DM reached slightly higher values in CZE, where the SMR from DM increased substantially from 11.9/100,000 to 45/100,000 and the SMR from CRD from $21.5 / 100,000$ to $48 / 100,000$.

\section{Trends of Potential Gains in Life Expectancy from 1996-2013 in Slovakia and Czech Republic}

During 1996-2013, CZE showed the highest impact on life expectancy of cancer diseases, an average of 3.61 years, followed by IHD, CVD, CRD, DM (Fig. 2). The highest PGLEs in SVK were observed for IHD, an average of 4.54, and secondly for cancer, an average of 3.3. Other diseases had the same position in both countries. Overall trends of PGLEs roughly paralleled the SMR trends.

As shown Figure 2, for CZE, the rising trend of PGLEs was the highest for DM, from 0.08 years in 1996 to 0.35 years in 2013, but the impact on life expectancy is negligible. On the contrary, the highest impacts on life expectancy resulted of elimination of cancer and ischaemic heart disease, respectively, from 3.65, 3.17 in 1996 to 3.31, 3.06 in 2013. It is visible that trends for cancer and IHD are decreasing, compared to rising trends of PGLEs of the same diseases in SVK. However, the highest decreasing trend was observed for PGLEs of CVD from 1.65 to 0.93 , a drop of $43 \%$, compared to a decrease of $7.34 \%$ from 1.13 to 1.05 in SVK. Conversely, PGLEs of CRD recorded almost four times higher 


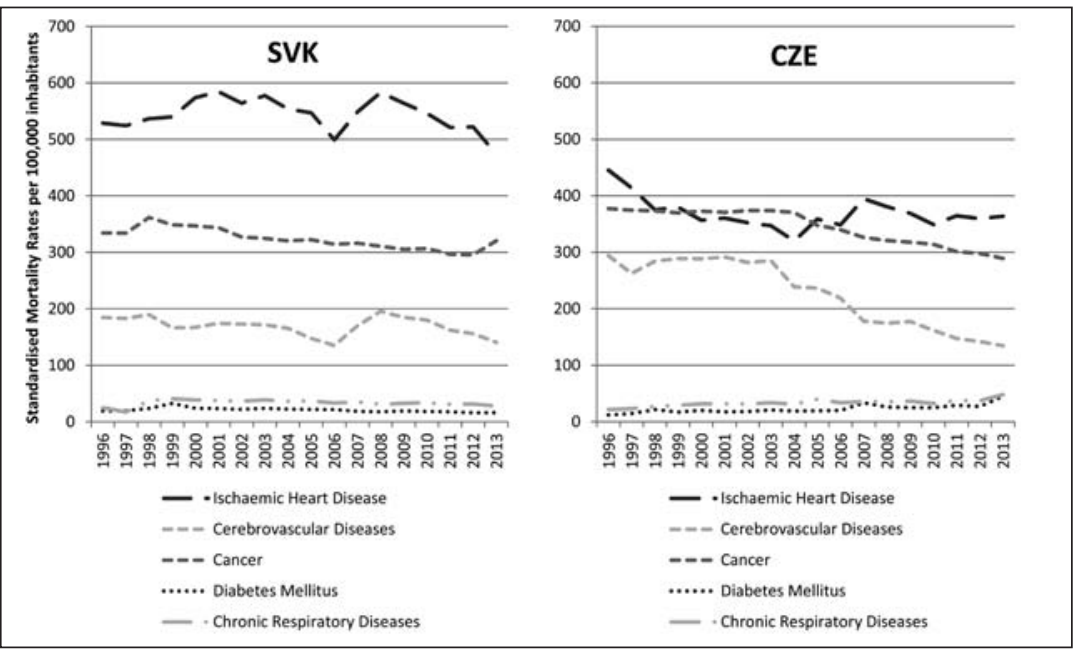

Fig. 1. Standardised mortality rates per 100,000 inhabitants for the groups of chronic diseases in Slovakia and Czech Republic, 1996-2013.
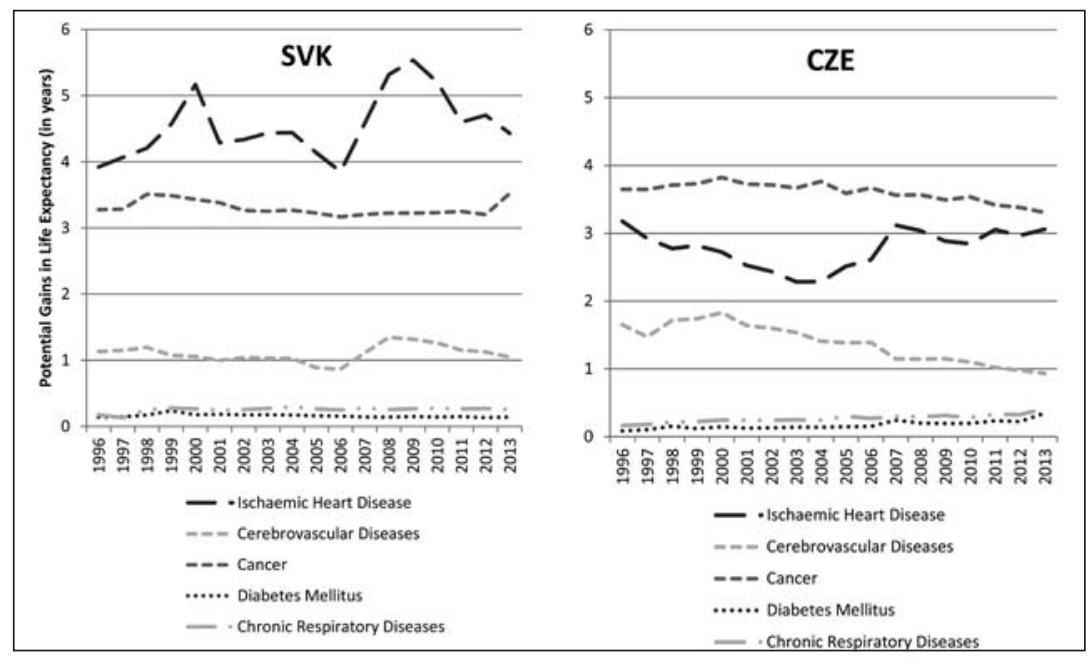

Fig. 2. Potential gains in life expectancy (in years) for the Slovak and Czech population by reductions of deaths for groups of chronic diseases, 1996-2013.

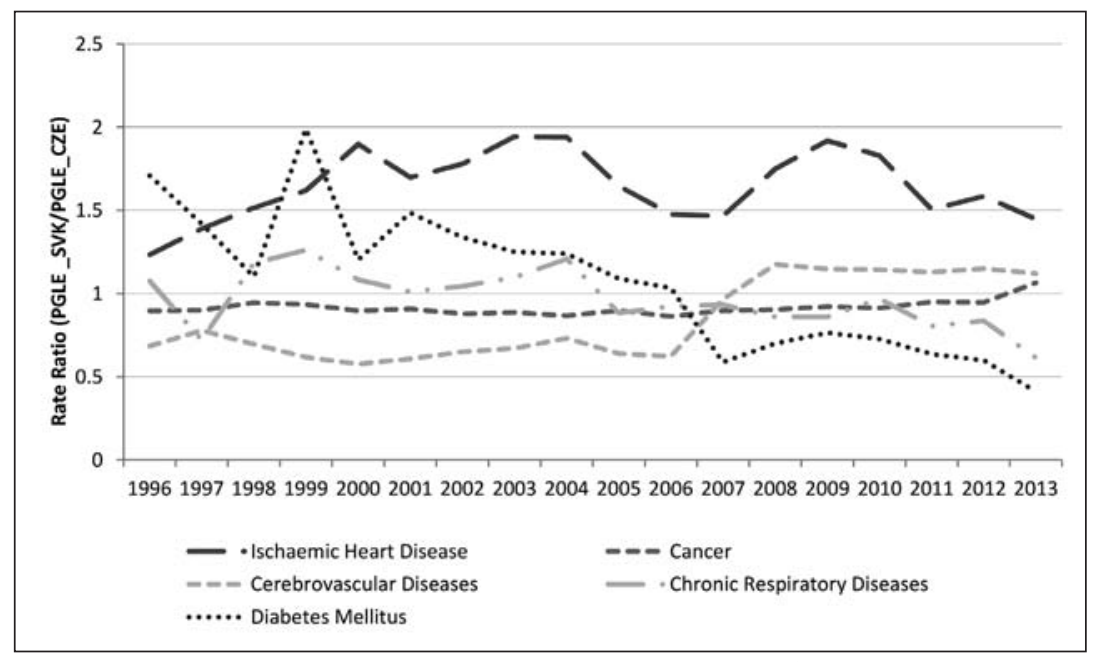

Fig. 3. Rate ratio of potential gains in life expectancy (PGLE) of the selected chronic diseases, 1996-2013. 
increase in CZE than in SVK, but the impact on life expectancy is very low.

To illustrate relative change, we calculated a rate ratio of PGLEs pertaining to the SVK and to the CZE (Fig. 3). The largest gap of PGLEs is evident for IHD, when SVK recorded an average of 1.65 greater gains compared to CZE during the whole period. On the contrary, ratios of PGLEs of CA reported the lowest variability, showing by $8 \%$ lower gains on average in SVK. During 1996-2006, DM disease elimination produced 1.35 higher PGLEs for SVK, subsequently, a reversal came in 2007 when gains of DM for SVK showed 0.59 times less than for CZE. The opposite results of rate ratios are seen in CVD, showing an average of 0.69 lower PGLEs for SVK till 2007, in the rest years gains demonstrated 1.14 times more than CZE. Rate ratio for CRD exhibited unstable development, once in favor of the SVK, then in favor of the CZE. Since 2005, SVK had recorded an average of 0.85 lower gains compared to CZE.

\section{Differences of Potential Gains in Life Expectancy Among age Groups Between Slovakia and Czech Republic in 2013}

Table 1 shows the PGLEs at birth by five-year age groups through the elimination in mortality from mentioned diseases in 2013, both for the Slovakia and Czech Republic. Comparing the countries, the PGLEs of ischaemic heart disease, cerebrovascular diseases and cancer were lower in the Czech Republic, on the contrary, PGLEs of diabetes mellitus and chronic respiratory diseases were higher.

As one would anticipate, these exclusions result in rather smaller increases in life expectancy at older ages (24).

In the Czech Republic, PGLEs of ischaemic heart disease mortality elimination were, unfortunately, increasing up to the 45-49 aged what means strengthening impacts of IHD on LE. Moreover, in Slovakia these impacts raised until the 75-79 aged meaning higher proportion of IHD mortality in elderly.

The PGLEs of cancer mortality decreased continuously until age $95+$, reaching a value that is very low compared with the PGLE at birth, from 3.52 to 0.25 in SVK and from 3.31 to 0.13 in CZE. It supposes that there are great differences across age groups.

Cerebrovascular diseases have reached the third largest impacts on LE. The PGLEs are nearly the same up to the 45-49 aged, the PGLE at the value 0.94 means the expected years of life which are the same for 49 years old people and younger. These people could gain most benefits from the CVD elimination. Similar case is visible in Slovakia but just until the 40-44 years old.

In the case of DM elimination, PGLEs are improving from 45-49 years old to the end in CZE and from 50-54 years old in SVK.

Trend of PGLEs in chronic respiratory diseases was decreasing from 30-34 age group in Slovakia, while in the Czech Republic drop was recorded until from 55-59 aged. So, after elimination of CRD deaths, a person at birth could be expected to live 0.41 years longer than the actual LE at birth (78.16 years). Equally, a

Table 1. Potential gains in life expectancy (in years) at age groups by elimination of the groups of chronic diseases, based on 2013 mortality data, in Slovakia and Czech Republic

\begin{tabular}{|c|c|c|c|c|c|c|c|c|c|c|}
\hline \multirow{2}{*}{ Age group } & \multicolumn{2}{|c|}{ IHD } & \multicolumn{2}{|c|}{$C A$} & \multicolumn{2}{|c|}{ CVD } & \multicolumn{2}{|c|}{ DM } & \multicolumn{2}{|c|}{ CRD } \\
\hline & SVK & CZE & SVK & CZE & SVK & CZE & SVK & CZE & SVK & CZE \\
\hline 00-00 & 4.43 & 3.06 & 3.52 & 3.31 & 1.05 & 0.93 & 0.14 & 0.35 & 0.25 & 0.41 \\
\hline 01-04 & 4.45 & 3.07 & 3.54 & 3.31 & 1.05 & 0.94 & 0.14 & 0.35 & 0.25 & 0.41 \\
\hline 05-09 & 4.46 & 3.07 & 3.53 & 3.31 & 1.05 & 0.94 & 0.14 & 0.35 & 0.25 & 0.41 \\
\hline 10-14 & 4.46 & 3.07 & 3.52 & 3.30 & 1.05 & 0.94 & 0.14 & 0.35 & 0.25 & 0.41 \\
\hline 15-19 & 4.47 & 3.07 & 3.51 & 3.30 & 1.06 & 0.94 & 0.14 & 0.35 & 0.25 & 0.41 \\
\hline 20-24 & 4.47 & 3.07 & 3.50 & 3.29 & 1.06 & 0.94 & 0.14 & 0.35 & 0.25 & 0.41 \\
\hline $25-29$ & 4.48 & 3.08 & 3.49 & 3.29 & 1.06 & 0.94 & 0.14 & 0.35 & 0.25 & 0.41 \\
\hline $30-34$ & 4.49 & 3.09 & 3.49 & 3.29 & 1.06 & 0.94 & 0.14 & 0.35 & 0.24 & 0.41 \\
\hline $35-39$ & 4.51 & 3.10 & 3.47 & 3.27 & 1.06 & 0.94 & 0.14 & 0.35 & 0.24 & 0.41 \\
\hline 40-44 & 4.52 & 3.10 & 3.44 & 3.24 & 1.06 & 0.94 & 0.14 & 0.35 & 0.24 & 0.41 \\
\hline $45-49$ & 4.53 & 3.11 & 3.39 & 3.19 & 1.05 & 0.94 & 0.14 & 0.34 & 0.24 & 0.41 \\
\hline $50-54$ & 4.54 & 3.09 & 3.27 & 3.09 & 1.04 & 0.93 & 0.13 & 0.34 & 0.23 & 0.41 \\
\hline $55-59$ & 4.54 & 3.07 & 3.07 & 2.93 & 1.03 & 0.93 & 0.13 & 0.34 & 0.22 & 0.40 \\
\hline $60-64$ & 4.54 & 3.03 & 2.75 & 2.66 & 1.02 & 0.92 & 0.12 & 0.33 & 0.20 & 0.39 \\
\hline $65-69$ & 4.55 & 2.96 & 2.32 & 2.26 & 1.00 & 0.92 & 0.11 & 0.32 & 0.18 & 0.36 \\
\hline $70-74$ & 4.56 & 2.89 & 1.84 & 1.77 & 0.95 & 0.91 & 0.10 & 0.30 & 0.16 & 0.32 \\
\hline 75-79 & 4.56 & 2.81 & 1.38 & 1.30 & 0.87 & 0.87 & 0.08 & 0.26 & 0.13 & 0.26 \\
\hline 80-84 & 4.54 & 2.69 & 0.97 & 0.87 & 0.77 & 0.81 & 0.06 & 0.23 & 0.10 & 0.19 \\
\hline 85-89 & 4.45 & 2.51 & 0.63 & 0.52 & 0.64 & 0.71 & 0.04 & 0.17 & 0.07 & 0.13 \\
\hline 90-94 & 4.35 & 2.17 & 0.37 & 0.27 & 0.47 & 0.55 & 0.02 & 0.11 & 0.04 & 0.08 \\
\hline $95+$ & 4.11 & 1.89 & 0.25 & 0.13 & 0.34 & 0.41 & 0.01 & 0.06 & 0.02 & 0.05 \\
\hline
\end{tabular}


person at 50-54 aged could live 0.41 years longer than actual LE at this age group (29.9 years).

\section{DISCUSSION}

The PGLE is one of the indicators explaining an effectiveness of health care system (10). Total elimination of a certain cause of death leads to the maximal number of years to which the life expectancy could be prolonged. The higher PGLE shows a greater burden of disease for health care system. Overall trends of PGLEs are highly correlated with the SMR trends.

Based on our findings, the greatest burden of diseases on life expectancy occurred after elimination of deaths due to IHD in SVK and due to CA in CZE. These results show that more effective public health interventions on ischaemic heart disease prevention are needed in SVK, and on cancer prevention in CZE.

The PGLEs of both deaths decreased from 1996 to 2013 in CZE compared to an increase in SVK, and continued to have a meaningful impacts on life expectancy. Although, the impacts of CA are higher in CZE, their differences between countries are the lowest from all considered diseases.

Among age groups in 2013, elimination of the IHD mortality would give more benefits for people over 50 years of age in SVK than in CZE, since decreasing PGLEs change was observed from 50 years of age in CZE while PGLEs were almost unchanging during all age groups in SVK. There was a substantial gap between PGLEs of IHD in CZE and in SVK, suggesting that Slovak public health interventions could be inspired by those in CZE. PGLEs of the eliminating CA reported that any age category was not excessive burdened in both countries.

Summary, PGLEs of IHD shows the greatest impact on LE in SVK, trend is increasing, and burden of all age groups is almost the same. In CZE, IHD has the second highest values of PGLE, trend is decreasing and people up to the 49 years old are burdened of IHD the most.

In SVK, CA shows the second greatest impact on LE, trend is increasing, and from 60 years old significant changes between age groups occurred. In CZE, CA has the greatest impact on LE, but trend is decreasing and impact is strongly decreasing. When considering other diseases, changes between age categories are not so remarkable.

PGLEs of CVD have the third highest impact on LE, both in SVK and CZE, however, they performed the highest percent decrease of all diseases in CZE compared to very low drop on SVK. Since 75 years old, greater percent change are visible between age categories in SVK than in CZE, what means more significant differences between age groups.

PGLEs of DM accounted for the highest increase in CZE, and impact of DM is worsening compared to SVK. Through the elimination of DM, age groups up to the 44 years old lost the most years of life.

It is necessary to solve CRD mainly in CZE because they increase faster than in SVK and their impact changes the most from 65 years old.

During 1996-2013, cardiovascular mortality was primarily influenced by the lifestyle of population, physical inactivity, eating fatty foods, lower access to interventional diagnostics and interventional therapy. At the beginning of the twenty-first century, cardiocenters have emerged resulting in a decrease of cardiovascular mortality in Slovakia during the beginning of the second decade of this century. Between 2010 and 2013, SMR from IHD dropped from 546.1/100,000 to 473.5/100,000 and SMR from CVD fell from 180.2/100,000 to 140.7/100,000 (Fig. 1). Nevertheless, mortality in 2013 in Slovakia was comparable to mortality in 1996 in the Czech Republic.

Data limitation lies in the unavailability of the absolute number of causes of death coded in ICD-10th by five-year age groups, in 2014 for the Czech Republic. So, we were compelled to analyse the time span 1996-2013.

In the future, there is the need to address also in CZE and SVK the emerging causes of death found recently to substantially influence the increase in NCD-mortality: poisoning including drug overdose, liver diseases and cirrhosis, and suicide $(25,26)$.

\section{CONCLUSIONS}

The main critical finding is the extensive difference in PGLEs of IHD between SVK and CZE. The reasons can result from many factors, for example economic, physical, environmental, social, health care, etc. that are mostly the same for chronic diseases and could be the subject of our further analyses. However, it is desirable to focus on the prevention of lifestyle diseases in both countries leading to extending of life expectancy. All actors who forming chronic diseases prevention, for example patients, primary health care, hospitals, media, schools, etc., play an important role in achieving prolonged life expectancy.

\section{Acknowledgement}

This work was supported by the VEGA Project No. 1/0929/14 "Multidimensional economic and financial evaluation of the implementation process and the use of one day health care and quantification of the financial impact on the health care system in the Slovak Republic“.

\section{Conflict of Interests}

None declared

\section{REFERENCES}

1. OECD.Stat. Health Status: Life expectancy [Internet]. [cited 2016 Apr 10]. Available from: http://stats.oecd.org/Index.aspx?DatasetCode=HEALTH STAT.

2. CPHR. National Human Development Report Slovak Republic 20012002. Bratislava: UNDP; 2002. (In Slovak.)

3. Maresova P, Mohelska H, Dolejs J, Kuca K. Socio-economic aspects of Alzheimer's Disease. Curr Alzheimer Res. 2015;12(9):903-11.

4. Gajdos O, Loncak V, Bartak M, Rogalewicz V. Cost of illness study of type 2 diabetes mellitus in the newly established diabetology outpatient facility in the Czech Republic. Value Health. 2015;18(7):A603-4.

5. WHO. Global health risks: mortality and burden of disease attributable to selected major risks [Internet]. Geneva: WHO; 2009 [cited 2016 May 10]. Available from: http://www.who.int/healthinfo/global_burden_disease/ global_health_risks/en/.

6. OECD. Health at a Glance 2015: OECD Indicators [Internet]. Paris: OECD Publishing; 2015 [cited 2016 Apr 6]. Available from: http://www. oecd-ilibrary.org/social-issues-migration-health/health-at-a-glance-2015_ health_glance-2015-en.

7. Mohelska H, Maresova P, Valis M, Kuca K. Alzheimer's disease and its treatment costs: case study in the Czech Republic. Neuropsychiatr Dis Treat. 2015 Sep 11;11:2349-54. 
8. Zelený T, Bencko V. Healthcare system financing and profits: all that glitters is not gold. Cent Eur J Public Health. 2015;23(1):3-7.

9. Ucieklak-Jez P, Bem A, Predkiewicz P. Effectiveness of allocation of health system non-financial resources. In: Bratianu C, Zbuchea A, Pinzaru F, Vatamanescu EM, Leon RD, editors. Local versus global. Strategica: International Academic Conference; 2015 Oct 29-31; Bucharest. Bucharest: SNSPA; 2015. p. 647-56.

10. Mackenbach JP, Kunst AE, Lautenbach H, Oei YB, Bijlsma F. Gains in life expectancy after elimination of major causes of death: revised estimates taking into account the effect of competing causes. J Epidemiol Community Health. 1999 Jan;53(1):32-7.

11. Lai D, Hardy RJ. Potential gains in life expectancy or years of potential life lost: impact of competing risks of death. Int J Epidemiol. 1999 Oct;28(5):894-8.

12. Liu P, Li Ch, Wang Y, Zeng $\mathrm{W}$, Wang $\mathrm{H}$, Wu $\mathrm{H}$, et al. The impact of the major causes of death on life expectancy in China: a 60-year longitudinal study. BMC Public Health. 2014 Nov 20;14:1193. doi: 10.1186/14712458-14-1193.

13. Conti S, Farchi G, Masocco M, Toccaceli V, Vichi M. The impact of the major causes of death on life expectancy in Italy. Int J Epidemiol. 1999;28(5):905-10.

14. Bleha B, Šprocha B, Vaňo B. Prognosis of population development in the Slovak Republic up to 2060. Bratislava: INFOSTAT; 2013. (In Slovak.)

15. Burcin B, Kučera T. Structural changes in mortality in the Czech Republic and Slovakia between 1991 and 2006. Demografie. 2008; 50:173-85. (In Czech.)

16. Mészáros J. Mortality. In: Vaňo B, editor. Population development in the Slovak Republic in 2011. Bratislava: INFOSTAT; 2011. p. 53-64. (In Slovak.)

17. Gavurová B, Vagašová T. Regional differences of standardised mortality rates for ischemic heart diseases in the Slovak Republic for the period 1996-2013 in the context of income inequality. Health Econ Rev. 2016;6:21. doi:10.1186/s13561-016-0099-1.
18. Šoltés V, Gavurová B. The possibilities of day surgery system development within the health policy in Slovakia. Health Econ Rev. 2014;4:35. doi:10.1186/s13561-014-0035-1.

19. Mészáros J. Methodological guide. The calculation of life tables. The calculation of Potential Years of Life Lost. Bratislava: INFOSTAT; 2000. (In Slovak.)

20. Arias E, Heron M, Tejada-Vera B. United States life tables eliminating certain causes of death, 1999-2001. Natl Vital Stat Rep. 2013;61(9):1-128.

21. European Commision. Revision of the European Standard Population. Report of Eurostat's task force. Luxembourg: Publications Office of the European Union; 2013.

22. Burcin B, Kučera T. Long-term trends in mortality of the population of the Czech Republic in the European context. In: Fialová L, et al. Population development in the Czech Republic 2007. Prague: Charles University, Faculty of Science; 2008. p. 111-25. (In Czech.)

23. Zachar D. The reform process in health care system - 2000-2012. In: Morvay K, editor. Health care system - markets, regulation and policy. Bratislava: INEKO; 2012. (In Slovak.)

24. Leyland AH, Dundas R, McLoone P, Boddy FA. Inequalities in mortality in Scotland, 1981-2001. Glasgow: MRC Social and Public Health Sciences Unit; 2007.

25. Shiels MS, Chernyavskiy P, Anderson WF, Best AF, Haozous EA, Hartge $\mathrm{P}$, et al. Trends in premature mortality in the USA by sex, race, and ethnicity from 1999 to 2014: an analysis of death certificate data. Lancet. 2017;389(10073):1043-54.

26. Zajacova A, Montez JK. Macro-level perspective to reverse recent mortality increases. Lancet. 2017;389(10073):991-2.

Received October 17, 2016 Accepted in revised form December 19, 2017 